\title{
Impact of Ejection Fraction on Long-Term Outcome After Elective Aortic Valve Replacement in Octogenarians With Aortic Stenosis
}

\author{
Kentaro Shibayama, MD; Hiroyuki Watanabe, MD; Minoru Tabata, MD; Shunsuke Sasaki, MD; \\ Toshihiro Fukui, MD; Jun Umemura, MD; Shuichiro Takanashi, MD; Tetsuya Sumiyoshi, MD
}

\begin{abstract}
Background: Aortic stenosis (AS) is increasingly common in the elderly population. A recent invention of transcatheter aortic valve implantation tends to tilt the risk-benefit balance to favor earlier elective intervention for AS. Hence, decision making for elective intervention in octogenarians gradually becomes important. However, the outcome after elective aortic valve replacement (eAVR) has not been evaluated adequately. This study aimed to identify risk factors after eAVR in octogenarians and investigate their influence on long-term outcome.
\end{abstract}

\begin{abstract}
Methods and Results: One hundred and thirty-seven consecutive Japanese octogenarians with AS who underwent eAVR were studied. The mean follow-up period was 35 \pm 22 (range, 0-88) months. Long-term overall survival rates after eAVR were $92.0 \%, 85.2 \%$ and $75.5 \%$ at 1,3 and 5 years, respectively. Cox proportional hazards model identified age [hazard ratio (HR) 1.23; 95\% confidence interval $(\mathrm{Cl}) 1.07-1.43 ; \mathrm{P}<0.01)$ ] and ejection fraction $(\mathrm{EF})<50 \%$ (HR 3.38; 95\% Cl 1.34-8.52; $\mathrm{P}<0.01$ ) as the risk factors of mortality. Post-eAVR survival rates in octogenarians with an $\mathrm{EF} \geq 50 \%$ and $<50 \%$ were $97.3 \%$ and $70.4 \%$ at 1 year, $90.1 \%$ and $65.3 \%$ at 3 years, and $84.3 \%$ and $39.2 \%$ at 5 years, respectively $(\mathrm{P}<0.0001)$.
\end{abstract}

Conclusions: Octogenarians with preserved LV systolic function before surgery have favorable long-term survival after eAVR. However, an EF $<50 \%$ influences the mortality in octogenarian patients. Therefore, eAVR should be considered for octogenarians with AS before the progression of LV impairment. (Circ J 2012; 76: 1761-1767)

Key Words: Aortic stenosis; Echocardiography; Elderly; Left ventricular dysfunction; Surgery

I $\mathrm{n}$ recent years, the continuous expansion of the elderly population in developed countries has resulted in a significant increase in the number of people aged over 80 years. Aortic stenosis (AS) is increasingly being diagnosed in octogenarians along with aging of the population and development of non-invasive diagnostic techniques, particularly 2dimensional (2D) color Doppler echocardiography. ${ }^{1-4}$

The ACC/AHA guidelines states that the risk-benefit balance might change to favor earlier intervention for AS as improved valve substitutes are developed and methods of valve replacement become safer. ${ }^{5}$ The current trend thus suggests that decision making on elective intervention in elderly patients with AS is gradually becoming more important due to recent invention of transcatheter aortic valve implantation. However, decision making on surgical intervention in elderly patients with AS is often difficult, even as an elective procedure. A study estimated that surgery was denied in $33 \%$ of elderly patients with AS, for reasons such as advanced age and left ventricular $(\mathrm{LV})$ systolic dysfunction [ejection fraction $(\mathrm{EF})<50 \%]^{6}$

Surgical aortic valve replacement (AVR) in octogenarians has been performed with acceptable 5-year survival, which varied between $52 \%$ and $73 \%$ in selected individuals. ${ }^{7-14}$ In contrast, most of the previous studies included subjects who underwent non-elective procedures, ${ }^{7-11,13}$ which is known to be a strong risk factor of operative mortality in octogenarians. ${ }^{11,15,16}$ Therefore, the long-term outcome and risk factors of elective AVR (eAVR) in octogenarians have not been adequately evaluated. Furthermore, the subjects of most previous studies were American and European octogenarians. Because there are racial differences in cardiac size and function, ${ }^{17}$ these racial features need to be taken into consideration when considering surgical intervention in Japanese octogenarians with AS. The purpose of the present retrospective study was to identify risk factors associated with post-eAVR mortality and investigate how they affect the long-term outcome after eAVR in Japanese octogenarians with AS.

Received January 6, 2012; revised manuscript received February 9, 2012; accepted February 20, 2012; released online April 3, 2012 Time for primary review: 17 days

Department of Cardiology (K.S., H.W., S.S., J.U., T.S.), Department of Cardiovascular Surgery (M.T., T.F., S.T.), Sakakibara Heart Institute, Tokyo, Japan

Mailing address: Kentaro Shibayama, MD, Sakakibara Heart Institute, 3-16-1 Asahi-cho, Fuchu, Tokyo 183-0003, Japan. E-mail: kshibaya@shi.heart.or.jp

ISSN-1346-9843 doi:10.1253/circj.CJ-12-0025

All rights are reserved to the Japanese Circulation Society. For permissions, please e-mail: cj@j-circ.or.jp 


\section{Methods}

\section{Study Population}

A retrospective study was conducted with 137 consecutive Japanese octogenarians who underwent eAVR for AS between July 2004 and October 2010 at the Department of Cardiovascular Surgery of the Sakakibara Heart Institute, Tokyo, Japan. Preoperative demographic and perioperative data were retrieved from our computerized database.

The primary end point was survival, which was obtained by reviewing inpatient records and follow-up records at outpatient clinics attended by discharged patients, and telephone interviews for a longer term outcome of 1 year or longer after surgery. This study was approved by the human ethics committee of the Sakakibara Heart Institute. Informed consent regarding participation in any clinical research was obtained from all subjects through the Sakakibara Heart Integrative Profile when patients were admitted to our hospital, and their data was available for this study.

\section{Echocardiography}

Comprehensive 2D and Doppler transthoracic echocardiography was performed at the Sakakibara Heart Institute in all patients within 2 months before and 1 week after AVR. A midterm follow-up echocardiography was performed at random from 3 months to 1 year after hospital discharge. A long-term follow-up echocardiography was performed routinely at 1 year after and beyond.

Peak transaortic velocity $(\mathrm{Vp})$ and mean transaortic pressure gradient (MPG) were measured by continuous wave Doppler using a multiwindow approach. The aortic valve area (AVA) and actual effective orifice area (EOA) were calculated by the continuity equation. Very severe AS was defined as $\mathrm{Vp}>5.0 \mathrm{~m} / \mathrm{s}, \mathrm{MPG}$ $>60 \mathrm{mmHg}$, and AVA $<0.60 \mathrm{~cm}^{2} .{ }^{18,19}$ Indexed AVA and EOA were defined as AVA and prosthetic EOA, respectively, divided by body surface area (BSA), and prosthesis-patient mismatch (PPM) was classified as severe (Indexed EOA $\leq 0.60 \mathrm{~cm}^{2} / \mathrm{m}^{2}$ ), moderate $\left(0.60<\right.$ Indexed EOA $\left.\leq 0.85 \mathrm{~cm}^{2} / \mathrm{m}^{2}\right)$ or non-significant (Indexed EOA $\left.>0.85 \mathrm{~cm}^{2} / \mathrm{m}^{2}\right){ }^{20-26}$ The $\mathrm{LV}$ mass was calculated using the M-mode method by the following formula: $1.04 \times[(\mathrm{LV}$ internal dimension + posterior LV wall thickness + interventricular septal thickness) ${ }^{3}-\mathrm{LV}$ diastolic diameter $\left.{ }^{3}\right] \times 0.8+0.6{ }^{27}$ The LV end-diastole volume, end-systolic volume and EF were calculated by using the biplane Simpson's rule on 2D echocardiography. The peak mitral inflow velocity of the early rapid filling wave $(\mathrm{E})$ was measured by pulsed wave Doppler. The peak mitral-annulus longitudinal velocity of the early diastolic wave (e') was measured by tissue Doppler. The ratio between E and e' (E/e') was used as a parameter of LV diastolic function.

\section{Surgical Procedures}

All surgical records were reviewed to obtain information on the type and size of the aortic valve prosthesis and concomitant coronary artery bypass graft surgery $(\mathrm{CABG})$ or valvular operations other than AVR.

eAVR was defined to be scheduled and to be performed more than $24 \mathrm{~h}$ after admission. ${ }^{28}$ In the present study, using bioprosthesis was indicated on the basis of the guideline. ${ }^{29}$ The patients who had a small aortic annulus (less than $18 \mathrm{~mm}$ ) were excluded from selection of using bioprosthesis.

\section{Anticoagulation After Operation}

The patients with a mechanical prosthesis underwent permanent anticoagulation with warfarin therapy and the patients with a bioprosthesis underwent persistent anticoagulation for
3 months, in which both international normalized ratio (INR) were maintained from 2.0 to 3.0 according to the guideline. ${ }^{29}$ Anticoagulation was used in patients with atrial fibrillation 3 months after their operation using bioprosthesis and beyond, in which the INR was also maintained from 2.0 to 3.0.

\section{Statistical Analysis}

Data are presented as mean \pm standard deviation for continuous variables, or as a number with percentage for categorical variables. To determine the predictors of mortality, the Cox proportional hazards model was used to estimate the risk for mortality associated with the following variables: age, ${ }^{4,11,13}$ NYHA III or IV, ${ }^{4}$ diabetes mellitus, ${ }^{4,13}$ renal impairment (GFR $<50 \mathrm{ml}),{ }^{8,13}$ chronic obstructive pulmonary disease, ${ }^{8,12}$ EuroSCORE II, ${ }^{30} \mathrm{EF}<50 \%,{ }^{5,6,10} \mathrm{CABG},{ }^{16}$ very severe AS $(\mathrm{Vp}>5.0 \mathrm{~m} / \mathrm{s}$, MPG $>60 \mathrm{mmHg}$, and AVA $<0.60 \mathrm{~cm}^{2}$ ), ${ }^{18,19}$ and PPM (severe: Indexed EOA $\leq 0.60 \mathrm{~cm}^{2} / \mathrm{m}^{2}$, moderate or severe: Indexed EOA $\left.\leq 0.85 \mathrm{~cm}^{2} / \mathrm{m}^{2}\right) .{ }^{20-26}$ The variables with probability values less than 0.25 in univariate analyses were included in the multivariate analysis. ${ }^{31}$

Follow-up survival curves were estimated by using the Kaplan-Meier method. For each patient included in this study, the corresponding mean age- and gender-specific annual mortality rate of the Japanese general population was obtained. These data were taken from Japanese life tables from 1962 to 2009 , which were provided by the Ministry of Health, Labour and Welfare. On the basis of these mortality data, the probability of cumulative expected survival was determined for the beginning of each year, and plotted as an expected survival curve.

Two-tailed probability values less than 0.05 were considered statistically significant. Statistical analysis was performed using the SPSS17.0 software (SPSS Inc, Chicago, IL, USA).

\section{Results}

\section{Clinical Characteristics}

Baseline characteristics and operative and postoperative data are outlined in Tables 1,2. The mean age of the patients was $83 \pm 2$ years (range, $80-93$ years). Sixty-nine percent $(n=95)$ of the patients were females. Careful medical interview and examination revealed some symptoms in all patients. The study population included patients who underwent a previous cardiac operation $(5 \%, n=7)$, NYHA class III or IV $(48 \%, n=66)$, moderate or severe aortic regurgitation $(7 \%, \mathrm{n}=9)$ and very severe AS $(53 \%, \mathrm{n}=72)$. The mean EuroSCORE II was $7.9 \pm$ $7.4 \%$. Twenty-nine patients $(21 \%)$ received a mechanical valve. Sixty-three $(46 \%)$ had concomitant $\mathrm{CABG}$, and 7 patients required CABG predominantly. Twenty $(15 \%)$ had concomitant valvular operations other than AVR. After AVR, 59 patients $(43 \%)$ had moderate or severe PPM, including 4 severe PPM $(3 \%)$. Thirty-one patients $(23 \%)$ had atrial fibrillation (AF), including $8(6 \%)$ with new onset after AVR.

\section{In-Hospital Mortality and Postsurgical Complications}

In-hospital mortality and early postsurgical complications are listed in Table 3. In-hospital deaths occurred in 5 patients (4\%). The 5 deaths included 4 cardiac deaths due to congestive heart failure in 3 patients $(2 \%)$ and acute myocardial infarction in 1 patient $(1 \%)$, and 1 non-cardiac death due to acute cholecystitis (1\%). Of the 5 patients who died, 3 patients (2\%) had combined AVR-CABG. Tachycardiac arrhythmias occurred in 14 patients (14\%), 13 of whom had AF and 1 had ventricular tachycardia. Stroke occurred in 4 patients (3\%) and cerebral hemorrhage in 1 patient $(1 \%)$. Eighty-five patients $(62 \%)$ had no postoperative complications. 


\begin{tabular}{|c|c|}
\hline & Mean \pm SD or $n(\%)$ \\
\hline \multicolumn{2}{|l|}{ Demographics and symptoms } \\
\hline Age (years) & $83 \pm 2$ \\
\hline Female & $95(69)$ \\
\hline Body height $(\mathrm{cm})$ & $151 \pm 8$ \\
\hline $\mathrm{BSA}\left(\mathrm{m}^{2}\right)$ & $1.5 \pm 0.2$ \\
\hline BMI $\left(\mathrm{kg} / \mathrm{m}^{2}\right)$ & $23 \pm 4$ \\
\hline Previous cardiac operation & $7(5)$ \\
\hline \multicolumn{2}{|l|}{ Clinical symptoms and signs } \\
\hline Shortness of breath & $118(86)$ \\
\hline Chest pain & $52(38)$ \\
\hline Syncope & $16(12)$ \\
\hline Congestive heart failure & $44(32)$ \\
\hline \multicolumn{2}{|l|}{ NYHA } \\
\hline Class I & $12(9)$ \\
\hline Class II & $59(43)$ \\
\hline Class III & $39(28)$ \\
\hline Class IV & $27(20)$ \\
\hline Atrial fibrillation & $38(28)$ \\
\hline \multicolumn{2}{|l|}{ Risk factors } \\
\hline Hypertension & $96(70)$ \\
\hline Hyperlipidemia & $57(42)$ \\
\hline DM & $28(20)$ \\
\hline Chronic renal failure & $20(15)$ \\
\hline \multicolumn{2}{|c|}{ Comorbidity and logistic EuroSCORE II } \\
\hline Hemodialysis & $5(4)$ \\
\hline Previous MI & $6(4)$ \\
\hline History of stroke & $20(15)$ \\
\hline COPD & $8(6)$ \\
\hline EuroSCORE II (\%) & $7.9 \pm 7.4$ \\
\hline \multicolumn{2}{|l|}{ Laboratory data } \\
\hline CRP (mg/dl) & $0.3 \pm 0.7$ \\
\hline GFR (ml/min) & $47 \pm 17$ \\
\hline $\mathrm{HbA}_{1 \mathrm{c}}(\%)$ & $5.6 \pm 0.8$ \\
\hline \multicolumn{2}{|l|}{ Echocardiographic data } \\
\hline Moderate or severe AR & $9(7)$ \\
\hline Very severe AS & $46(34)$ \\
\hline $\mathrm{EF}<50 \%$ & $27(20)$ \\
\hline
\end{tabular}

$\mathrm{SD}$, standard deviation; BSA, body surface area; BMI, body mass index; NYHA, New York Heart Association; DM, diabetes mellitus; $\mathrm{MI}$, myocardial infarction; COPD, chronic obstructive pulmonary disease; CRP, C-reactive protein; GFR, glomerular filtration rate; $A R$, aortic regurgitation; AS, aortic stenosis; EF, ejection fraction.

\section{Long-Term Outcome and Risk Factors of Mortality}

Clinical follow-up data on the primary end point was available for all 137 patients (100\%). During an estimated followup period of $35 \pm 22$ months (range, $0-88$ months), a total of 18 patients had died after hospital discharge. Of these 18 patients, 5 patients $(28 \%)$ died due to a cardiac cause, including 3 sudden deaths, 5 patients $(28 \%)$ due to a cerebrovascular cause $(3$ strokes, 1 subdural hematoma due to falling and 1 subarachnoid hemorrhage) and 8 patients $(44 \%)$ due to miscellaneous causes ( 3 malignancies, 2 chronic renal failures, 2 infections and 1 senility). The estimated overall survival after eAVR was $92.0 \%$ at 1 year, $85.2 \%$ at 3 years, and $75.5 \%$ at 5 years (Figure 1), which was similar to the expected survival curve.

Table 4 shows the results of univariate and multivariate

\begin{tabular}{|lc|}
\hline \multicolumn{2}{|l}{ Table 2. Operative and Postoperative Characteristics (n=137) } \\
Valve prosthesis & $\mathbf{n}(\%)$ \\
Mechanical valve & $29(21)$ \\
Valve size & \\
$16 \mathrm{~mm}$ & $2(1)$ \\
$17 \mathrm{~mm}$ & $12(9)$ \\
$18 \mathrm{~mm}$ & $1(1)$ \\
$19 \mathrm{~mm}$ & $51(37)$ \\
$20 \mathrm{~mm}$ & $1(1)$ \\
$21 \mathrm{~mm}$ & $46(34)$ \\
$23 \mathrm{~mm}$ & $24(18)$ \\
Combined procedures & \\
Concomitant CABG & \\
EF $\geq 50 \%$ & $48(35)$ \\
EF <50\% & $15(11)$ \\
Other valvular operation & $20(15)$ \\
Postoperative characteristics & \\
PPM & \\
Severe & $4(3)$ \\
Moderate & $55(40)$ \\
NYHA class III+IV at hospital discharge & $3(2)$ \\
Atrial fibrillation after eAVR & $31(23)$ \\
Warfarin use after eAVR & $65(47)$ \\
\hline
\end{tabular}

CABG, coronary artery bypass grafting; EF, ejection fraction; PPM, prosthesis-patient mismatch; NYHA, New York Heart Association; eAVR, elective aortic valve replacement.

\begin{tabular}{|lc|}
\hline \multicolumn{2}{|c|}{ Table 3. Postsurgical Complications in Hospital $(\mathbf{n}=\mathbf{1 3 7})$} \\
& $\mathbf{n}(\%)$ \\
Death & $5(4)$ \\
Shock & $1(1)$ \\
Stroke or cerebral hemorrhage & $5(4)$ \\
Acute renal failure & $4(3)$ \\
Myocardial infarction & $1(1)$ \\
Tachycardiac arrhythmia & $14(10)$ \\
Permanent atrio-ventrical block & $1(1)$ \\
Gastrointestinal hemorrhage & $3(2)$ \\
Tamponade & $1(1)$ \\
Pulmonary congestion & $7(5)$ \\
Mediastinitis & $3(2)$ \\
Pericarditis & $1(1)$ \\
Intracardiac infection & $2(2)$ \\
\hline
\end{tabular}

analyses of risk factors for mortality. The Cox proportional hazards model revealed that age [per 1-year increment: hazard ratio (HR) 1.23; 95\% confidence interval (CI) 1.07-1.43; $\mathrm{P}<0.01$ ) ] and $\mathrm{EF}<50 \%$ (HR 3.38; 95\%CI 1.34-8.52; $\mathrm{P}<0.01$; Figure 2) were independent negative predictors for long-term survival. Survival rates following eAVR in octogenarians with $\mathrm{EF} \geq 50 \%(\mathrm{n}=110)$ and $<50 \%(\mathrm{n}=27)$ were $97.3 \%$ and $70.4 \%$ at 1 year, $90.1 \%$ and $65.3 \%$ at 3 years, and $84.3 \%$ and $39.2 \%$ at 5 years, respectively $(\mathrm{P}<0.0001)$.

\section{Serial Echocardiographic Data}

All 137 patients completed echocardiography within 2 months before and 1 week after AVR (100\%). Mid- and long-term follow-up echocardiographic data were available for 88 pa- 


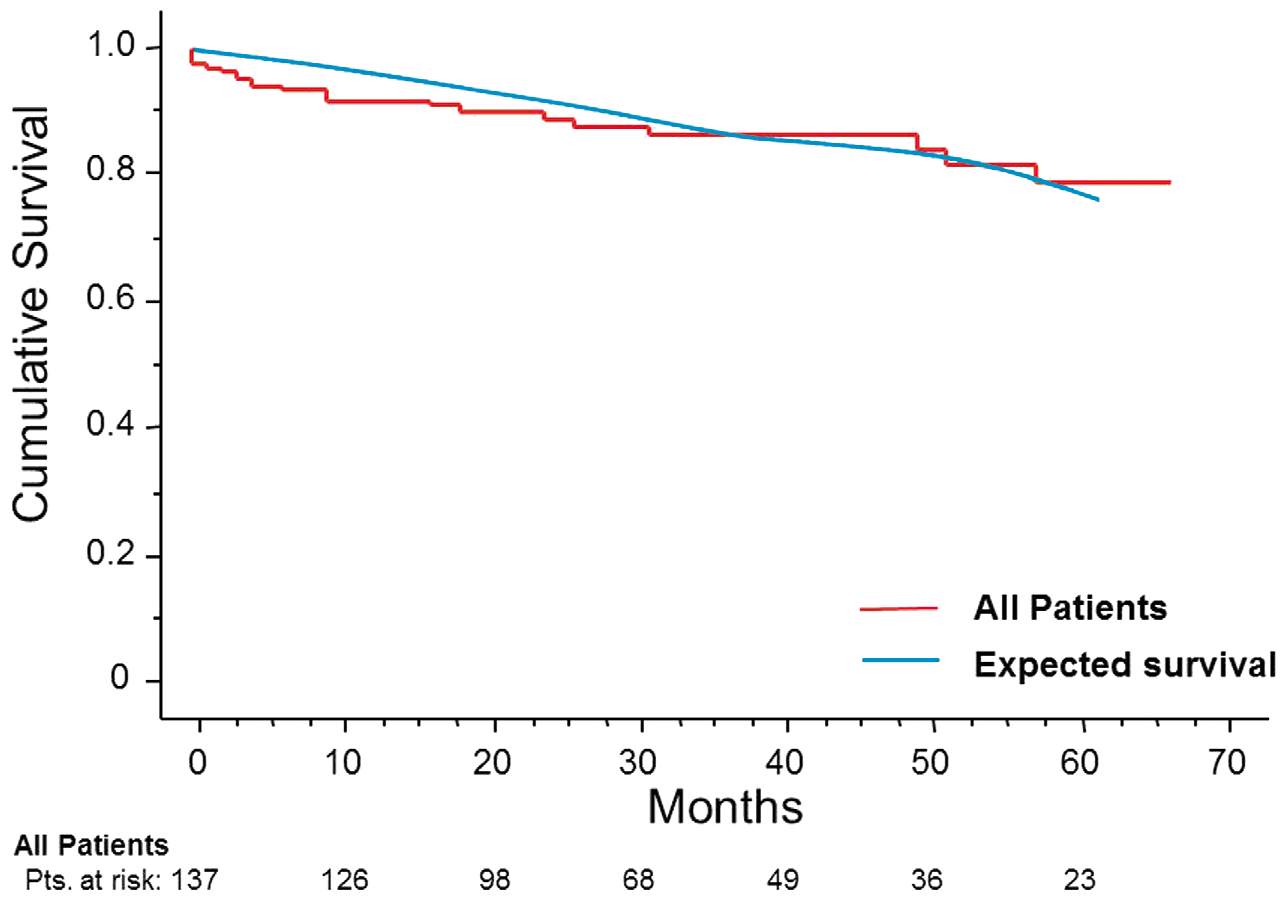

Figure 1. Overall survival curve in octogenarians $(n=137)$ with AS after elective AVR and expected survival curve in Japanese octogenarians. AS, aortic stenosis; AVR, aortic valve replacement.

\begin{tabular}{|c|c|c|c|c|}
\hline & \multicolumn{2}{|c|}{ Univariate } & \multicolumn{2}{|c|}{ Multivariate } \\
\hline & $\mathrm{HR}[95 \% \mathrm{Cl}]$ & $P$ value & $\mathrm{HR}[95 \% \mathrm{Cl}]$ & $P$ value \\
\hline Age & 1.19 [1.04-1.37] & 0.01 & $1.23[1.07-1.43]$ & $<0.01$ \\
\hline NYHA III-IV & $2.38[0.99-5.66]$ & 0.05 & $1.64[0.64-4.24]$ & 0.31 \\
\hline Diabetes mellitus & 3.26 [1.34-7.91] & $<0.01$ & $2.16[0.82-5.71]$ & 0.12 \\
\hline Renal impairment (GFR <50 ml) & 1.38 [0.58-3.25] & 0.47 & & \\
\hline COPD & 0.53 [0.07-3.98] & 0.54 & & \\
\hline EuroSCORE II & $1.05[1.01-1.09]$ & 0.04 & $1.01[0.96-1.06]$ & 0.73 \\
\hline$E F<50 \%$ & $4.70[2.07-10.70]$ & $<0.001$ & $3.38[1.34-8.52]$ & $<0.01$ \\
\hline Concomitant CABG & $1.49[0.65-3.37]$ & 0.34 & & \\
\hline Very severe AS & $0.47[0.18-1.28]$ & 0.14 & $0.38[0.12-1.23]$ & 0.11 \\
\hline \multicolumn{5}{|l|}{ PPM } \\
\hline Severe & 1.83 [0.42-8.02] & 0.42 & & \\
\hline Moderate or severe & $1.11[0.49-2.52]$ & 0.81 & & \\
\hline
\end{tabular}

The definition of very severe $A S: V p>5.0 \mathrm{~m} / \mathrm{s}, M P G>60 \mathrm{mmHg}$, and $A V A<0.60 \mathrm{~cm}^{2}$.

The definition of severe PPM: Indexed EOA $\leq 0.60 \mathrm{~cm}^{2} / \mathrm{m}^{2}$, and moderate or severe PPM: Indexed EOA $\leq 0.85 \mathrm{~cm}^{2} / \mathrm{m}^{2}$. $\mathrm{HR}$, hazard ratio; $\mathrm{Cl}$, confidence interval; EOA, effective orifice area. Other abbreviations as in Tables 1,2.

tients $(64 \%)$ and 110 patients $(80 \%)$, respectively (Table 5).

The preoperative echocardiographic data [mean \pm standard deviation (range)] showed an EF of $58 \pm 11 \%$ (24-80\%), LV

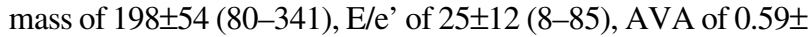
$0.19 \mathrm{~cm}^{2}\left(0.21-1.0 \mathrm{~cm}^{2}\right), \mathrm{Vp}$ of $5.1 \pm 1.1 \mathrm{~m} / \mathrm{s}(2.3-7.6 \mathrm{~m} / \mathrm{s})$ and a MPG of $60 \pm 26 \mathrm{mmHg}(11-148 \mathrm{mmHg})$. Although the mean EF did not change significantly 1 week after AVR compared to baseline, it increased significantly at follow up. Of 22 patients with an $\mathrm{EF}<50 \%$ at the performed follow-up echocardiography, all patients had improved LV systolic function at follow up, with 17 patients (77\%) showing an improvement by $10 \%$ or more. The mean LV volume, mean LV mass, mean $\mathrm{Vp}$, mean MPG and mean RVSP were significantly reduced 1 week after AVR and the improvements were maintained at follow up. The mean E/e' did not change at follow up compared to baseline.

\section{Discussion}

Accompanying the continuous expansion of the elderly population, AS has become an increasingly common cardiovascular disease in octogenarians. ${ }^{1-4}$ Because the risk-benefit balance 


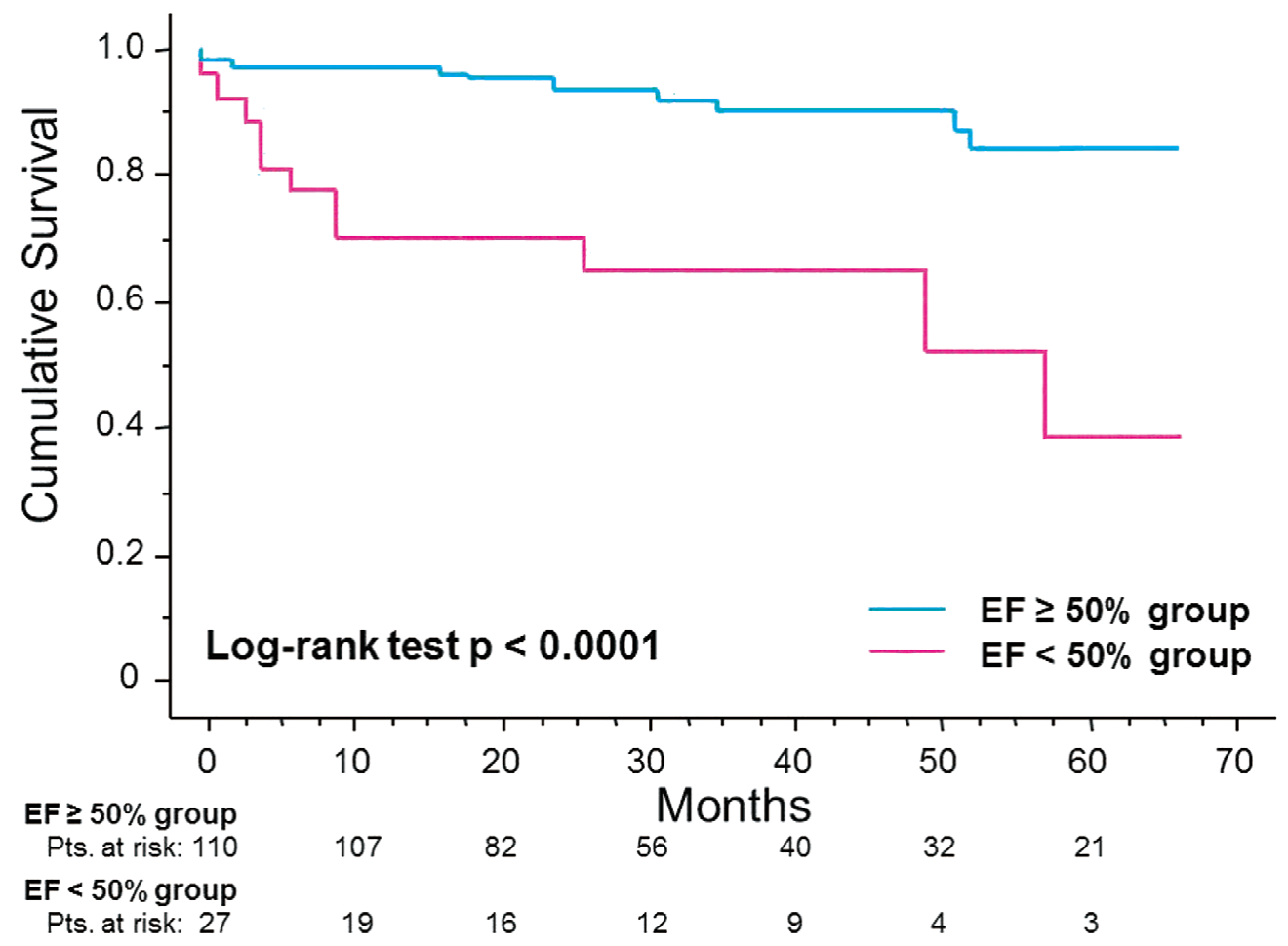

Figure 2. Post-eAVR survival rates of octogenarians stratified by preoperative EF of $50 \%$. Table at the bottom shows the number of patients at risk at 10 months after AVR. eAVR, elective aortic valve replacement; EF, ejection fraction.

\begin{tabular}{|c|c|c|c|c|}
\hline \multirow{2}{*}{ ECG data (mean $\pm S D)$} & \multirow{2}{*}{$\begin{array}{l}\text { Preoperative } \\
\quad(n=137)\end{array}$} & \multirow{2}{*}{$\begin{array}{c}1 \text { week after AVR } \\
(n=137)\end{array}$} & \multicolumn{2}{|c|}{ Follow-up } \\
\hline & & & Mid-term $(n=88)$ & Long-term $(n=110)$ \\
\hline Follow-up (days) & & $7 \pm 2$ & $188 \pm 67$ & $448 \pm 202$ \\
\hline $\mathrm{EF}(\%)$ & $58 \pm 11$ & $58 \pm 10$ & $62 \pm 7^{*}$ & $62 \pm 6^{*}$ \\
\hline $\mathrm{EDV}(\mathrm{ml})$ & $93 \pm 38$ & $73 \pm 25^{\star \star}$ & $73 \pm 24^{\star *}$ & $72 \pm 23^{\star *}$ \\
\hline $\mathrm{ESV}(\mathrm{ml})$ & $42 \pm 28$ & $32 \pm 18^{\star \star}$ & $28 \pm 13^{\star \star}$ & $28 \pm 11^{\star \star}$ \\
\hline LV mass & $198 \pm 54$ & $171 \pm 44^{\star *}$ & $158 \pm 38^{* *}$ & $150 \pm 42^{* *}$ \\
\hline LV mass/BSA (g/m²) & $136 \pm 34$ & $118 \pm 29^{\star \star}$ & $108 \pm 24^{* *}$ & $102 \pm 26^{* *}$ \\
\hline$E / e^{\prime}$ & $25 \pm 12$ & $23 \pm 11$ & $23 \pm 11$ & $23 \pm 11$ \\
\hline AVA or EOA $\left(\mathrm{cm}^{2}\right)$ & $0.59 \pm 0.19$ & $1.39 \pm 0.40^{\star *}$ & $1.38 \pm 0.35^{\star \star}$ & $1.48 \pm 0.39^{* *}$ \\
\hline Indexed AVA or EOA $\left(\mathrm{cm}^{2} / \mathrm{m}^{2}\right)$ & $0.41 \pm 0.13$ & $0.96 \pm 0.26^{\star \star}$ & $0.93 \pm 0.25^{\star \star}$ & $1.00 \pm 0.27^{\star *}$ \\
\hline $\mathrm{Vp}(\mathrm{m} / \mathrm{s})$ & $5.1 \pm 1.1$ & $2.6 \pm 0.5^{\star \star}$ & $2.5 \pm 0.5^{\star \star}$ & $2.4 \pm 0.5^{\star \star}$ \\
\hline MPG $(\mathrm{mmHg})$ & $60 \pm 26$ & $15 \pm 7^{* *}$ & $14 \pm 6^{\star *}$ & $13 \pm 6^{* *}$ \\
\hline $\mathrm{RVSP}(\mathrm{mmHg})$ & $34 \pm 13$ & $29 \pm 8^{* *}$ & $31 \pm 7^{\star \star}$ & $30 \pm 7^{\star *}$ \\
\hline
\end{tabular}

Comparison with preoperative data, ${ }^{*} P<0.05$ and ${ }^{* *} P<0.001$

ECG, echocardiographic; AVR, aortic valve replacement; EF, ejection fraction; EDV, end-diastolic volume; ESV, endsystolic volume; LV, left ventricular; BSA, body surface area; E/e', rapid filling wave/peak early diastolic wave mitralannulus velocity; AVA, aortic valve area; EOA, effective orifice area; Vp, peak transaortic velocity; MPG, mean transaortic pressure gradient; RVSP, right ventricular systolic pressure.

might change to favor earlier elective intervention in octogenarians with AS due to the development of valve intervention, ${ }^{5}$ decision making on elective intervention in octogenarians is gradually becoming more important. Furthermore, the subjects in most of the previous studies were American and European octogenarians, and it is necessary to address racial differences when making a decision of eAVR in Japanese octogenarians with AS. ${ }^{17}$ The purpose of the present retrospective study was to identify risk factors associated with eAVR and investigate how they affect the long-term outcome after eAVR in Japanese octogenarians with AS.

\section{Long-Term Outcome After eAVR}

The overall survival rates in this study were $92.0 \%, 85.2 \%$, and $75.5 \%$ at 1,3 and 5 years, respectively. These rates were slightly higher than many previous reports on AVR in octoge- 
narians, which ranged from $52 \%$ to $73 \%$ at 5 years. ${ }^{7-14}$ The survival rate depends largely on the prevalence of risk factors in the study population. The difference from previous studies might be due to the fact that our study evaluated only elective procedures while past studies included also non-elective surgeries (6-56\%). ${ }^{7-11,13}$ Kolh et al $^{11}$ reported survival rates after elective surgery of $88.1 \%, 84.3 \%$ and $78.1 \%$ at 1,3 and 5 years respectively, which were similar to our results. However, their study did not evaluate the risk factors of eAVR in octogenarians because their study population included non-elective surgeries. To the best of our knowledge, our report is the first to identify risk factors and long-term outcome of eAVR in octogenarians with AS. One study on 36 Japanese elderly patients reported that the survival rates at 1,3 and 5 years after AVR were $93.6 \%, 79.6 \%$ and $79.6 \%$, respectively, but that study included only 5 octogenarians. ${ }^{3}$ Moreover, the follow-up period was short and the number of patients was too low for multivariate analysis in that report.

A total of 18 deaths occurred after hospital discharge in our study, but there were only 5 cardiac deaths (28\%). In previous reports, cardiac deaths occupied less than one-third of all deaths after hospital discharge in octogenarians who underwent AVR. ${ }^{11,32}$ Non-cardiac causes, such as cerebrovascular disease, chronic kidney disease (CKD), malignant disease and infection, had a strong influence on long-term outcome after AVR in octogenarians with AS. The relationship between LV systolic dysfunction and stroke was reported in a previous study, ${ }^{33}$ therefore, it was thought that stroke increased when a low $\mathrm{EF}$ was present. It was reported that systolic heart failure worsened kidney function and was associated with increased mortality. ${ }^{34}$ Hence, LV systolic dysfunction might increase the mortality after eAVR due to CKD. However, we have no data to indicate the relationship between malignancy and low EF or between infection and low EF.

\section{Prognostic Factors for Mortality}

Our study identified an EF $<50 \%$ and age as the risk factors for mortality after eAVR for octogenarians with AS, and demonstrated that LV systolic dysfunction in octogenarians undergoing eAVR had an unfavorable impact on long-term survival (Figure 2).

Age is one of the strong risk factors of long-term outcome after AVR in octogenarians. ${ }^{6,11-13}$ However, age is not a predictor of poor long-term outcome compared with the corresponding age-matched expected survival. ${ }^{35,36}$ Therefore, the ACC/AHA guideline describes that all elderly patients with symptomatic AS might be considered for AVR and that the decision to proceed with surgery depends on many factors other than old age. ${ }^{5}$

The ACC/AHA guideline states that the survival outcome is similar in symptomatic patients with normal LV function and in those with moderate depression of contractile function. ${ }^{5}$ However, most previous studies in octogenarians reported LV dysfunction as a strong predictor of mortality after $\mathrm{AVR}^{4,8,16}$ and some reports revealed that even a slight decrease in EF might be a risk factor. ${ }^{10,13}$ Therefore, particularly in an advanced aged population, even mild LV dysfunction might strongly influence long-term outcome after AVR.

Kitai et $\mathrm{al}^{19}$ recommended early intervention for very severe AS because these patients had a significantly poorer natural history than those with severe AS. In octogenarians who underwent eAVR for AS, we demonstrated that very severe AS before surgery was not a risk factor of mortality. Therefore, our result supports the proposal of early elective intervention in octogenarians with very severe AS.
PPM was not significantly associated with mortality in our study. Although controversy remains over the impact of PPM in the elderly, Moon et $\mathrm{a}^{24}$ demonstrated that PPM did not influence long-term survival after AVR in patients older than 70 years. Our result in Japanese octogenarians was in agreement with theirs.

\section{Serial Changes in Echocardiographic Parameters}

In our study, preoperative LV chamber size and LV mass, which were larger than normal, decreased significantly toward the normal values at follow up. ${ }^{17}$ Previous studies have shown significant regression of $\mathrm{LV}$ dimensions after AVR, ${ }^{37,38}$ and a 20-30\% decrease in LV mass index within the first year was reported. ${ }^{39}$ Our result was consistent with these studies.

We also studied the serial changes of LV systolic and diastolic function on echocardiography. LV systolic function improved significantly in most of the patients with depressed LV systolic function before surgery, as was also shown by other studies. ${ }^{39-41}$ In contrast, LV diastolic function did not change significantly at follow up. It has been reported that advanced diastolic dysfunction indirectly reflects non-reversible structural myocardial abnormalities, although a reduced LV systolic function often reflects the after load excess in patients with $\mathrm{AS}{ }^{42}$ We speculate that diastolic function deteriorates with old age, and is exacerbated by AS, and that diastolic dysfunction in octogenarians with AS might reflect non-reversible myocardial impairment in our study.

\section{Racial Differences Between Japanese and Other Developed Countries' Octogenarian Patients}

Japanese octogenarians in this study $(n=137$, female 69\%) have a significantly smaller mean BSA $\left(1.5 \mathrm{~m}^{2}\right)$ and mean body mass index (BMI) $\left(23 \mathrm{~kg} / \mathrm{m}^{2}\right)$ than European octogenarians who underwent AVR for AS in a previous study $(\mathrm{n}=149$, female $54 \%$ ), in whom a mean BSA was $1.8 \mathrm{~m}^{2}$ and a mean BMI was $28 \mathrm{~kg} / \mathrm{m}^{2} .{ }^{26}$ The percentage of PPM in this study (43\%) was not larger than in previous American and European elderly studies, which varied between $60 \%$ and $63 \% .^{24-26}$ Therefore, PPM is not the inherent problem, particularly in Japanese octogenarians.

\section{Study Limitations}

Our study has several limitations. First, the number of patients was low and the follow-up period was short. However, regarding the validity of the Cox proportional hazards model, the estimated $\mathrm{P}$ values and CIs for the 2 risk factors should be valid because there were 23 post-AVR deaths among 137 octogenarians in the present study. Second, the mechanism underlying the association between a slight decrease in EF and long-term survival is not clear because of the low number of deaths. Finally, there was no control group in this study, which limits our ability to assess the efficacy of surgical intervention. From an ethical standpoint, a therapeutic decision for each individual patient has to be made by the attending physician according to current practice guidelines.

\section{Conclusion}

Japanese octogenarians with AS and preserved LV systolic function have favorable long-term survival after eAVR. However, an EF less than $50 \%$ is a risk factor for mortality after eAVR in octogenarian patients. Therefore, eAVR should be considered for octogenarians with AS before the progression of LV impairment. 


\section{Disclosures}

None.

\section{References}

1. Iung B, Baron G, Butchart EG, Delahaye F, Gohlke-Bärwolf C, Levang $\mathrm{OW}$, et al. A prospective survey of patients with valvular heart disease in Europe: The Euro Heart Survey on Valvular Heart Disease. Eur Hear J 2003; 24: 1231-1243.

2. Nkomo VT, Gardin JM, Skelton TN, Gottdiener JS, Scott CG, EnriquezSarano M. Burden of valvular heart diseases: A population-based study. Lancet 2006; 368: 1005-1011.

3. Ohno M, Hashimoto Y, Suzuki M, Matsumura A, Isobe M. Current state of symptomatic aortic valve stenosis in the Japanese elderly. Circ J 2011; 75: 2474-2481.

4. Yamane K, Hirose H, Youdelman BA, Bogar LJ, Diehl JT. Conventional aortic valve replacement for elderly patients in the current era. Circ J 2011; 75: 2692-2698.

5. Bonow RO, Carabello BA, Kanu C, de Leon AC Jr, Faxon DP, Freed $\mathrm{MD}$, et al. ACC/AHA 2006 guidelines for the management of patients with valvular heart disease: A report of the American College of Cardiology/American Heart Association Task Force on Practice Guidelines (writing committee to revise the 1998 Guidelines for the Management of Patients With Valvular Heart Disease): Developed in collaboration with the Society of Cardiovascular Anesthesiologists: Endorsed by the Society for Cardiovascular Angiography and Interventions and the Society of Thoracic Surgeons. Circulation 2006; 114: e84-e231.

6. Iung B, Cachier A, Baron G, Messika-Zeitoun D, Delahaye F, Tornos $\mathrm{P}$, et al. Decision-making in elderly patients with severe aortic stenosis: Why are so many denied surgery? Eur Heart $J$ 2005; 26: 2714 2720.

7. Sundt TM, Bailey MS, Moon MR, Mendeloff EN, Huddleston CB, Pasque MK, et al. Quality of life after aortic valve replacement at the age of $>80$ years. Circulation 2000; 102: III70-III74

8. Gehlot A, Mullany CJ, Ilstrup D, Schaff HV, Orzulak TA, Morris JJ, et al. Aortic valve replacement in patients aged eighty years and older: Early and long-term results. J Thorac Cardiovasc Surg 1996; 111: $1026-1036$.

9. Carrier M, Khalil A, Tourigny A, Solymoss BC, Pelletier LC. Aortic valve replacement in octogenarians: Risk factors for early and late mortality. Ann Thorac Surg 2007; 83: 1651-1657.

10. Chiappini B, Camurri N, Loforte A, Di Marco L, Di Bartolomeo R, Marinelli G. Outcome after aortic valve replacement in octogenarians. Ann Thorac Surg 2004; 78: 85-89.

11. Kolh P, Kerzmann A, Honore C, Comte L, Limet R. Aortic valve surgery in octogenarians: Predictive factors for operative and longterm results. Eur J Cardiothorac Surg 2007; 31: 600-606.

12. Bakaeen FG, Chu D, Ratcliffe M, Gopaldas RR, Blaustein AS, Venkat $\mathrm{R}$, et al. Severe aortic stenosis in a veteran population: Treatment considerations and survival. Ann Thorac Surg 2010; 89: 453-458.

13. Florath I, Albert A, Boening A, Ennker IC, Ennker J. Aortic valve replacement in octogenarians: Identification of high-risk patients. Eur J Cardiothorac Surg 2010; 37: 1304-1310.

14. Asimakopoulos G, Edwards MB, Taylor KM. Aortic valve replacement in patients 80 years of age and older: Survival and cause of death based on 1100 cases: Collective results from the UK Heart Valve Registry. Circulation 1997; 96: 3403-3408.

15. Kolh P, Kerzmann A, Lahaye L, Gerard P, Limet R. Cardiac surgery in octogenarians; peri-operative outcome and long-term results. Eur Heart J 2001; 22: 1235-1243.

16. Speziale G, Nasso G, Barattoni MC, Esposito G, Popoff G, Argano V, et al. Short-term and long-term results of cardiac surgery in elderly and very elderly patients. J Thorac Cardiovasc Surg 2011; 141: $725-731$.

17. Daimon M, Watanabe H, Abe Y, Hirata K, Hozumi T, Ishii K, et al. Normal values of echocardiographic parameters in relation to age in a healthy Japanese population: The JAMP study. Circ J 2008; 72: $1859-1866$

18. Rosenhek R, Zilberszac R, Schemper M, Czerny M, Mundigler G, Graf S, et al. Natural history of very severe aortic stenosis. Circulation 2010; 121: $151-156$

19. Kitai T, Honda S, Okada Y, Tani T, Kim K, Kaji S, et al. Clinical outcomes in non-surgically managed patients with very severe versus severe aortic stenosis. Heart 2011; 97: 2029-2032.

20. Rao V, Jamieson WR, Ivanov J, Armstrong S, David TE. Prosthesispatient mismatch affects survival after aortic valve replacement. Circulation 2000; 102: III5-III9.
21. Blais C, Dumesnil JG, Baillot R, Simard S, Doyle D, Pibarot P. Impact of valve prosthesis-patient mismatch on short-term mortality after aortic valve replacement. Circulation 2003; 108: 983-988.

22. Ruel M, Rubens FD, Masters RG, Pipe AL, Bédard P, Hendry PJ, et al. Late incidence and predictors of persistent or recurrent heart failure in patients with aortic prosthetic valves. $J$ Thorac Cardiovasc Surg 2004; 127: 149-159.

23. Mohty D, Malouf JF, Girard SE, Schaff HV, Grill DE, EnriquezSarano ME, et al. Impact of prosthesis-patient mismatch on longterm survival in patients with small St Jude Medical mechanical prostheses in the aortic position. Circulation 2006; 113: 420-426.

24. Moon MR, Lawton JS, Moazami N, Munfakh NA, Pasque MK, Damiano RJ Jr. POINT: Prosthesis-patient mismatch does not affect survival for patients greater than 70 years of age undergoing bioprosthetic aortic valve replacement. J Thorac Cardiovasc Surg 2009; 137: $278-283$

25. Vicchio M, Della Corte A, De Santo LS, De Feo M, Caianiello G, Scardone M, et al. Prosthesis-patient mismatch in the elderly: Survival, ventricular mass regression, and quality of life. Ann Thorac Surg 2008; 86: $1791-1797$.

26. Hernandez-Vaquero D, Calvo D, Garcia JM, Lozano I, Morales C, Naya JL, et al. Influence of patient-prosthesis mismatch in the octogenarian undergoing surgery for aortic valve replacement due to severe stenosis. Rev Esp Cardiol 2011; 64: 774-779.

27. Devereux RB, Alonso DR, Lutas EM, Gottlieb GJ, Campo E, Sachs I, et al. Echocardiographic assessment of left ventricular hypertrophy: Comparison to necropsy findings. Am J Cardiol 1986; 57: 450-458.

28. Copeland GP, Jones D, Walters M. POSSUM: A scoring system for surgical audit. Br J Surg 1991; 78: 355-360.

29. The Japanese Circulation Society. Guidelines for surgical and interventional treatment of valvular heart disease (JCS 2007). http://www. j-circ.or.jp/guideline/pdf/JCS2007_matsuda_h.pdf (in Japanese) (Accessed February, 9, 2012).

30. Lebreton G, Merle S, Inamo J, Hennequin JL, Sanchez B, Rilos Z, et al. Limitations in the inter-observer reliability of EuroSCORE: What should change in EuroSCORE II? Eur J Cardiothorac Surg 2011; 40: $1304-1308$.

31. Katz MH. Multivariable analysis: A practical guide for clinicians $1^{\text {st }}$ ed. Cambridge: Cambridge University Press, 1999.

32. Straumann E, Kiowski W, Langer I, Grädel E, Stulz P, Burckhardt D, et al. Aortic valve replacement in elderly patients with aortic stenosis. Br Heart J 1994; 71: 449-453.

33. Hays AG, Sacco RL, Rundek T, Sciacca RR, Jin Z, Liu R, et al. Left ventricular systolic dysfunction and the risk of ischemic stroke in a multiethnic population. Stroke 2006; 37: 1715-1719.

34. McAlister FA, Ezekowitz J, Tonelli M, Armstrong PW. Renal insufficiency and heart failure: Prognostic and therapeutic implications from a prospective cohort study. Circulation 2004; 109: 1004-1009.

35. Gilbert T, Orr W, Banning AP. Surgery for aortic stenosis in severely symptomatic patients older than 80 years: Experience in a single UK centre. Heart 1999; 82: 138-142.

36. Kvidal P, Bergström R, Hörte LG, Ståhle E. Observed and relative survival after aortic valve replacement. J Am Coll Cardiol 2000; 35: $747-756$.

37. Linares Vicente JA, Lacambra Blasco I, Portero Perez P, Ortas Nadal MR, Simo Sanchez B, Pascual Calleja I, et al. Sustained benefit of left ventricular remodelling after valve replacement for aortic stenosis. Cardiol J 2009; 16: 68-72.

38. Dinh W, Nickl W, Smettan J, Kramer F, Krahn T, Scheffold T, et al. Reduced global longitudinal strain in association to increased left ventricular mass in patients with aortic valve stenosis and normal ejection fraction: A hybrid study combining echocardiography and magnetic resonance imaging. Cardiovasc Ultrasound 2010; 8: 29.

39. Jin XY, Zhang ZM, Gibson DG, Yacoub MH, Pepper JR. Effects of valve substitute on changes in left ventricular function and hypertrophy after aortic valve replacement. Ann Thorac Surg 1996; 62: 683-690.

40. Pereira JJ, Lauer MS, Bashir M, Afridi I, Blackstone EH, Stewart WJ, et al. Survival after aortic valve replacement for severe aortic stenosis with low transvalvular gradients and severe left ventricular dysfunction. J Am Coll Cardiol 2002; 39: 1356-1363.

41. Rothenburger M, Drebber K, Tjan TD, Schmidt C, Schmid C, Wichter $\mathrm{T}$, et al. Aortic valve replacement for aortic regurgitation and stenosis, in patients with severe left ventricular dysfunction. Eur J Cardiothorac Surg 2003; 23: 703-709.

42. Gjertsson P, Caidahl K, Farasati M, Odén A, Bech-Hanssen O. Preoperative moderate to severe diastolic dysfunction: A novel Doppler echocardiographic long-term prognostic factor in patients with severe aortic stenosis. J Thorac Cardiovasc Surg 2005; 129: 890-896. 